\title{
New Wine in Old Bottles: Current Developments in Digital Delivery and Dissemination
}

\author{
PAUL AYRIS \\ Chair, LIBER Access Division, Director of UCL Library Services and UCL \\ Copyright Officer; University College London, Gower Street, London WC1E \\ 6BT, UK. E-mail: p.ayris@ucl.ac.uk
}

The purpose of this paper is to identify and assess current developments in scholarly publishing in Europe. Current models for disseminating content have limitations and Open Access models of publishing have been endorsed by the European Universities Association. The Harvard mandate for the deposit of materials in Open Access repositories is a bold new development, and the community is watching it with interest. It is possible that e-books may be the next large form of content to be made available to the user. Users certainly express interest in using this form of material. However, current library systems need to be developed in order to cope with this mass of new content. E-theses, available in Open Access from institutional repositories, are a form of content that is made much more visible than the paper equivalents. The DART-Europe portal, supported by LIBER (Association of European Research Libraries) currently provides access to 100,000 research theses in 150 European Universities. At an institutional and academic level, however, much remains to be done to embed Open Access into the landscape: the current situation is described in a new report for UCL (University College London), produced by RAND Europe.

\section{Open access: new publishing models}

Brussels 2007

Open Access has made significant progress in the European Information landscape. The Brussels Conference of January 2007 marks a significant point in the history of the development of Open Access approaches to the dissemination of research outputs. ${ }^{1}$ In my presentation at that meeting, The Future of Scholarly Publishing, I made a number of points that explain why European universities are 
keen to embrace such new publishing opportunities. Research-led universities have, as a core part of their mission, the development and dissemination of knowledge to benefit the world and the future.

In such an environment, what do academics actually want? The answer is not that they necessarily want money. As authors, researchers want visibility for their research outputs and an expectation that that visibility will be as widespread as possible. As readers, they want to have access to a very wide spread of content to support their work. As both authors and readers, they want transparent delivery of materials 24/7, any time, any place, anywhere - the so-called Martini principle. These are illustrated in Figure 1.

Many researchers, particularly those working in science and medicine, feel that current commercial models of publication do not deliver on all these agendas.

Some of the reasons for this unease are explained by Figure 2, which is taken from work by Matthew Cockerill at BioMed Central in 2004. ${ }^{2}$ Dr Cockerill looked at the totality of the research, funded by the British taxpayer, which is produced by

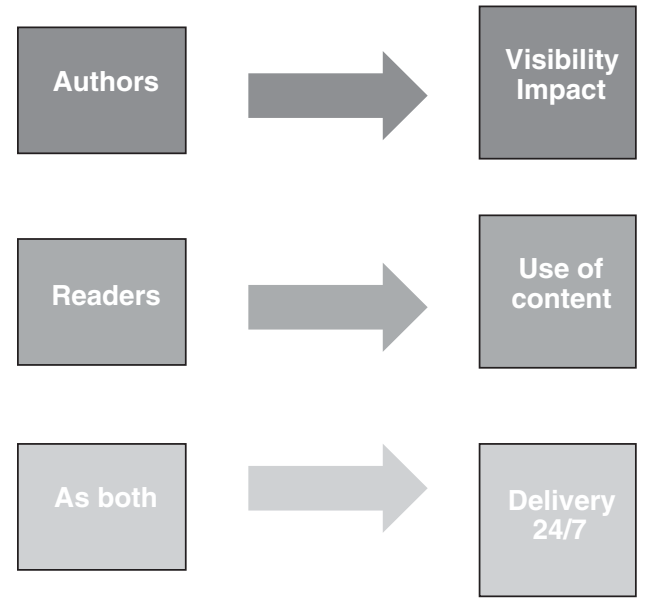

Figure 1. The needs of authors and readers from publication

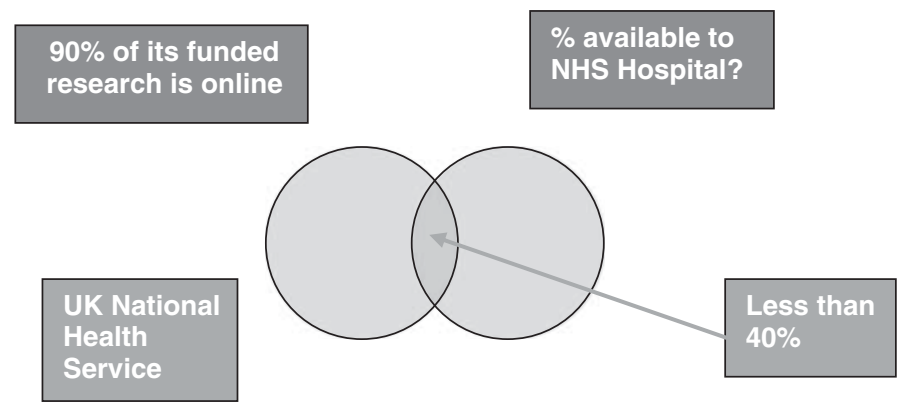

Figure 2. Availability of funded NHS research to NHS Hospitals 
the National Heath Service. He saw that $90 \%$ of that research is available online. He then looked to see what percentage of that research was available to medical and health staff throughout the NHS. His finding was that less than $40 \%$ was so available - a disappointing return on investment for the public purse.

The potential of Open Access to open up NHS research to the general health science community in the UK was recognised by Peter Hill in his recent report on NHS library provision, entitled Report of a National Review of NHS Health Library Services in England: From Knowledge to Health in the 21st Century. ${ }^{3}$ This review highlighted the centrality of library, knowledge and information services within the NHS and described four key purposes for library and knowledge services:

(1) Clinical decision making by patients, their carers as appropriate, and health professionals

(2) Commissioning decision and health policy making

(3) Research

(4) Lifelong learning by health professionals.

Recommendation 30 of the review acknowledged the important work by Matthew Cockerill and suggested that the percentage of NHS-funded research that should be freely available should be 100\%. Recommendation 41 also acknowledged that 'the direction of travel seems to be towards open access to published research output'. Chapter 17 of the Review stated:

One key principle should be that the public and patients should have access to the same knowledge and evidence base as professionals. Moves towards open access make this more achievable.

The review recommended that the NHS work with Higher Education in England to push forward on an Open Access agenda. Recommendation 46 acknowledged that:

The HE SHERPA ${ }^{4}$ network is acknowledged as a model of best practice. This is another area where there is a possibility for partnership working between HE and the NHS in repository development, and this should be explored.

Time will tell whether the National Health Service in the UK can adopt Open Access models, thereby making all the outputs of NHS-funded research available to all. The issue has been noted, and it is clear that the relevant UK Government Department, the Department of Health, will monitor work undertaken to implement the findings of the Hill review.

\section{European recommendations}

On 26 March 2008, the European Universities Association issued an endorsement of Open Access models for dissemination, which will do much to bring 
attention to these issues in European Universities. ${ }^{5}$ The chair of the Working Group, Sijboldt Noorda, led the membership to issue a striking endorsement of Open Access. The Group's membership included a number of senior university library staff from across Europe - from Finland, France, Greece, the Netherlands, Portugal, Spain, Sweden, the UK, and Belgium. Many of these individuals are noted supporters of Open Access and it is not difficult to hear a library voice in the final recommendations of the Working Group.

The EUA made some recommendations for University leadership:

- The basic approach for achieving this [Open Access] should be the creation of an institutional repository or participation in a shared repository.

- University institutional policies should require that their researchers deposit (self-archive) their scientific publications in their institutional repository upon acceptance for publication.

- University policies should include copyright in institutional intellectual property rights (IPR) management.

- University institutional policies should explore also how resources could be found and made available to researchers for author fees to support the emerging 'author pays model' of Open Access.

It also made recommendations for National Rectors' Conferences:

- All National Rectors' Conferences should work with national research funding agencies and governments in their countries to implement the requirement for self-archiving of research publications in institutional repositories and other appropriate Open Access repositories.

- National Rectors' Conferences should attach high priority to raising the awareness of university leadership to the importance of Open Access policies in terms of enhanced visibility, access and impact of their research results.

It made recommendations for the European University Association itself, as a body representative of European Higher Education:

- EUA should continue to contribute actively to the policy dialogue on Open Access at European levels with a view to a self-archiving mandate for all research results arising from EU research programme/ project funding.

The recommendations are a powerful statement from one of Europe's leading bodies of University Vice-Chancellors. However, the recommendations are not a mandate. The EUA has no power to tell its members what to do, for universities are autonomous, self-governing corporate bodies. The recommendations are just that - recommendations for best practice. 
The EUA's statements for its own Vice-Chancellors are particularly powerful. The EUA has come out explicitly to say that the principal way by which a university can achieve the objective of Open Access is to set up its own repository, or to have access to a shared repository. At the time of writing, the OpenDOAR Directory of Open Access Repositories ${ }^{6}$ lists 590 academic Open Access repositories in Europe. Table 1 takes that total number and compares it with totals available in other continents. Currently, from this statistic, Europe is performing well. However, this approach masks a more variable picture across Europe. OpenDOAR also counts the number of repositories by country as a proportion of the total number worldwide. This puts European performance in a less healthy position. European repository development seems to be embedded in only a handful of countries and these are to be found in Northern Europe. This is illustrated in Table 2. The OpenDOAR statistics help to illustrate why the EUA

Table 1. Proportion of academic Open Access repositories by continent

\begin{tabular}{lcr}
\hline \hline Continent & Number & $\%$ \\
\hline Europe & 590 & 48 \\
North America & 356 & 29 \\
Asia & 131 & 11 \\
Australasia & 72 & 6 \\
South America & 51 & 4 \\
Africa & 18 & 1 \\
Caribbean & 1 & 0 \\
Central America & 1 & 0 \\
\hline
\end{tabular}

Table 2. Proportion of academic Open Access repositories by country

\begin{tabular}{lcr}
\hline \hline Country & Number & $\%$ \\
\hline USA & 308 & 25 \\
UK & 132 & 11 \\
Germany & 129 & 11 \\
Japan & 69 & 6 \\
Australia & 59 & 5 \\
Netherlands & 45 & 4 \\
Canada & 43 & 4 \\
Italy & 42 & 3 \\
(54 others) & 393 & 32 \\
& Total 1200 repositories \\
\hline
\end{tabular}


recommendations are needed and which European countries have made the most progress in setting up Open Access repository infrastructures.

\section{Harvard mandate}

A major new development in the Open Access arena took place at Harvard in February 2008:

The Faculty of Arts and Sciences of Harvard University is committed to disseminating the fruits of its research and scholarship as widely as possible ... Each Faculty member grants to the President and Fellows of Harvard College permission to make available his or her scholarly articles and to exercise the copyright in those articles. In legal terms, the permission granted by each Faculty is a nonexclusive, irrevocable, paidup, worldwide license to exercise any and all rights under copyright relating to his or her scholarly articles, in any medium, and to authorize others to do the same, provided that the articles are not sold for a profit ...

To assist the University in distributing the articles, each Faculty member will provide an electronic copy of the final version of the article at no charge ... The Provost's Office may make the article available to the public in an open-access repository...

The policy will be reviewed after three years and a report presented to the Faculty. $^{7}$

Reactions to the mandate from librarians and academics seem positive. As Paul Courant from Michigan made clear, 'The big news in the Harvard vote is that it helps all of us to focus on the main point - that scholarly publishing, through a variety of mechanisms, is first and foremost about making scholarship public, not making money. ${ }^{8}$ The Harvard approach is an interesting practical illustration of how a university might put into practice a recommendation for Open Access, such as that espoused by the EUA. In the UK, for example, where a university may waive its rights to ownership of copyright in research outputs, granting it back to academics, an institutional mandate would carry no force. Universities cannot mandate Open Access publication where they have no right to do so. The Harvard approach is a viable approach because it is the members of faculty themselves, not the university, that are taking the lead. It is the academics, as copyright holders, who empower the Provost's Office to disseminate their research outputs from an Open Access repository by granting the Office a non-exclusive licence to do so. It will be interesting to see how many other universities globally follow Harvard's pioneering example.

\section{E-books}

A topic, which is of growing interest to research libraries and their users, is that of e-books. A Working Group, established by Ex Libris in conjunction with its 
user communities ELUNA and IGeLU, has spent some time looking at this issue and it presented a paper on emerging trends at the 2008 IGeLU meeting in Madrid in September 2008. ${ }^{9}$ The members of the Working Group ${ }^{10}$ were asked to examine all aspects of e-books from a broad perspective: how they are acquired, managed, described, discovered, and delivered. The purpose of the Working Group's report is to help identify how the Ex Libris community can tackle the emerging issue of e-book provision. A number of illuminating trends emerged from the study.

It was apparent to the Working Group that the challenges inherent in managing e-books could easily dwarf the well-known complexities of e-journals. The multitude of issues which the Working Group identified can be listed as:

- Variety of formats

- Purpose and use

- Diversity of software and hardware products/platforms

- Information supply chains

- Digital rights management

- Widely varying pricing models

- Licensing models and ownership

- Lack of agreement on standards and specification

- Digital curation

- Metadata issues

- Discovery and accessibility

- User attitudes and usage statistics

The Working Group also looked for other e-book studies, which would inform its deliberations. One of these studies is the SuperBook study from UCL, which is a collaboration between UCL's School of Library, Archive and Information Studies and UCL Library Services. ${ }^{11}$ Figure 3 is taken from the emerging work of the SuperBook study and gives an indication of what users themselves feel about e-books. Columns to the right of the diagram, with positive numerical values, show levels of user approval; columns to the left of the diagram with negative numerical values show levels of dissatisfaction. These are self-reported results; the answers reflect what users themselves said when questioned about the value of e-books. The biggest perceived advantage of e-books was the ability to make copies, followed by a perception that they were more up-to-date than other forms of publication. It is not necessarily true that e-books are more up-to-date, but this is what the respondents felt. The biggest disadvantages were seen to be 'ease of annotation', 'ease of marking a place' and 'ease of reading'. These are serious disadvantages because they may suggest that e-books themselves have no place in a scholarly environment. Perhaps the best way to interpret these negative results is to see them as a snapshot of user opinion at the start of what is an 


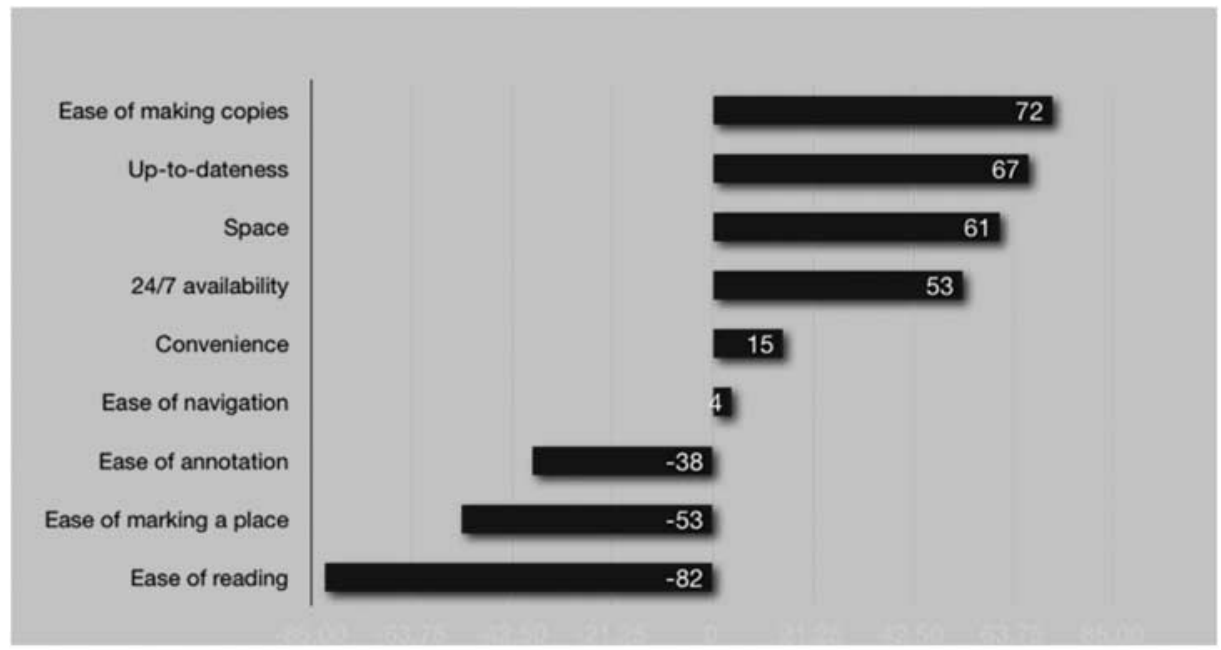

\section{Perceptions of e-books: \\ b baseline data $(n=760)$

Figure 3. Perceptions of e-books by users in UCL

emerging e-book market. For example, since this baseline study was undertaken, Sony has produced its e-book reader. ${ }^{12}$ This device can hold up to 160 e-books and, in terms of use, mimics in a convincing way the feel and experience of reading paper copy. In this respect, therefore, the findings of the SuperBook project may well change as user attitudes to new developments in the e-book market mature.

The Working Group established by Ex Libris, ELUNA and IGeLU looked at a number of issues:

- Discovery

- Locating/linking

- Management

- Delivery

In terms of the world of e-book products, the Working Group characterised the landscape in the terms portrayed in Figure 4.

Here, the library's traditional print collection is represented on the left-hand side of the diagram. There are clearly overlaps between this collection and commercial e-books. Some of these latter digital texts may be licensed locally by a library or the library may choose not to license/buy them. Then there is the swiftly-growing number of free e-books that are available on the internet - perhaps the results of digitisation by Google Books or from institutional digitisation programmes. 


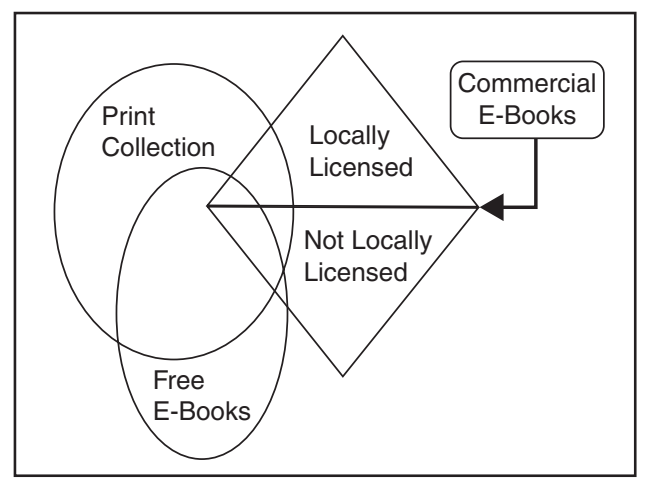

Figure 4. The world of e-books

There are overlaps here, both with a library's traditional print collection and commercially-available e-books.

In terms of Discovery, the Working Group tried to determine exactly which e-books users would expect to find in a search. Two possible solutions to this question were identified and these are presented in Figure 5. The Working Group agreed that the user would always want to know whether a print copy was available alongside the e-book. Hence, in both options, the discovery of a print copy is included as a 'must-have'. Common to both options is the discovery of commercially-purchased or commercially-licensed e-books. The difference in the two options is the discovery of freely-available e-books in the course of a search. Option 1 omits the range of free e-books that are available on the internet, where a library does not have the equivalent paper or e-copy. Option 2 includes all such freely-available e-books. The opinion of the present writer is that Option 2 is much the better option, because it gives users access to the maximum amount of material. It also mirrors current practice in e-journals and so-called Big Deals, where the whole of a publisher's content is commonly made available to users, whether or not the library subscribes to the equivalent e-copy.

Where will this discovery take place? The Working Group took the view that such discovery would happen through the library's catalogue or OPAC. Such a view was supported by a finding in the SuperBook study. Using the technique of deep log analysis, the UCL researchers looked at how users found e-books. In this study, $21 \%$ of the users surveyed found e-books via Google, as opposed to $38 \%$ who found them via the library catalogue. Other routes scored much lower points - federated searching $(5 \%)$ and via aggregators $(11 \%){ }^{13}$

In terms of metadata, the Working Group agreed that high quality metadata would be needed for discovery. The Group assumed that most e-book metadata would be acquired in large batches from e-book packages or from lists 


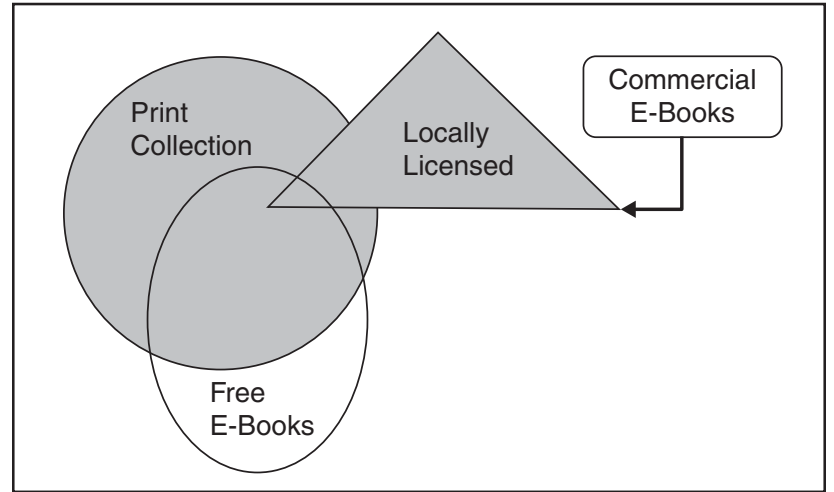

Option 1

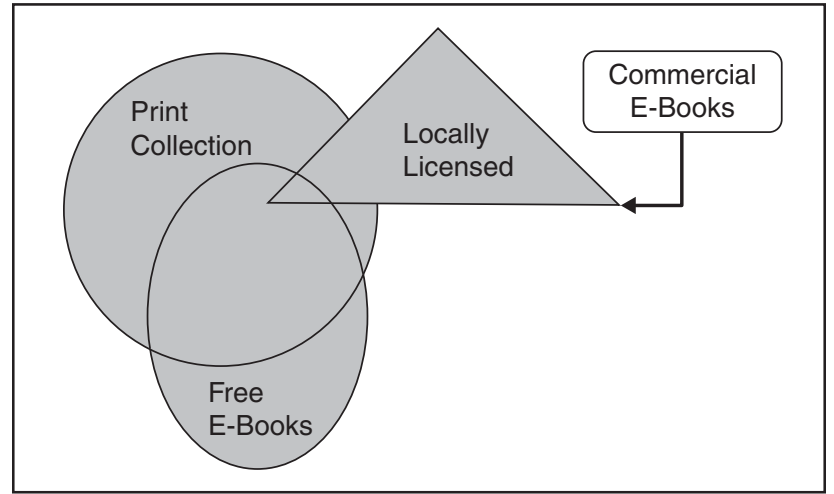

Option 2

Figure 5. Two options for the discovery of e-books in a search

of freely-available e-books. The Group posited the need for sophisticated de-duplication in metadata records at three levels:

- Duplicate copies

- Different manifestations of the same work

- Full FRBRisation

The Group acknowledged that versions, editions and the like have always created complexity. Mass digitisation projects add more complexity since digitisation creates duplicates of materials in local collections; and different projects create duplicate e-copies and e-versions. In terms of other discovery issues, meta searching the full content of e-books was not seen as an immediate priority. The Group also felt that browsing was not required for e-book discovery, because the scale of the task makes browsing problematic. The Group noted that browsing is deprecated in most current OPACs and new discovery systems. 


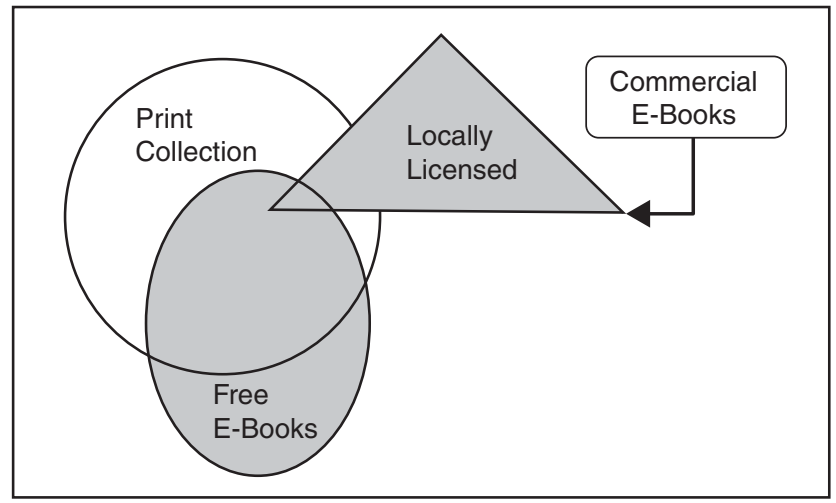

Figure 6. Linking options for e-books

The second issue, which the e-books Group considered, was locating and linking. There are problems in this area. Identifiers (the basis of most linking) are problematic for e-books. They are sparse or non-existent for retrospective digitisation outputs. There are also differing identifier assignment practices (manifestations, components, etc). There is also the question of how to tackle differing versions and editions of a work. The Group noted that there is no algorithmic linking for e-books. The recommendation from the Group was that there should be OpenURL linking for both licensed and free e-books (Figure 6).

The Group also thought that there should be OpenURL linking to local paper book collections and OpenURL linking to alternative editions.

The final issue the Working Group discussed was e-book delivery. While not identifying this as an immediate need, the Group considered that linkage at the chapter, page, or image level to e-books would eventually become essential. In such a scenario, there would be a case for the provision of a local platform for e-book storage and delivery.

The list of subjects, which the Working Group identified, clearly shows that there are a large number of issues to be tackled before e-books become embedded in the Information landscape. Nonetheless, as the SuperBook study shows, users see advantages in e-book delivery and, for the moment at least, identify the library as the place where the discovery of books, in paper or e-format, is made.

\section{E-theses}

One of the types of content that is gaining greater visibility and greater importance to the research community is research theses. There is a growing movement to make such theses discoverable, where possible, in Open Access. Services are beginning to be created to allow the discovery of such materials. The DART-Europe 


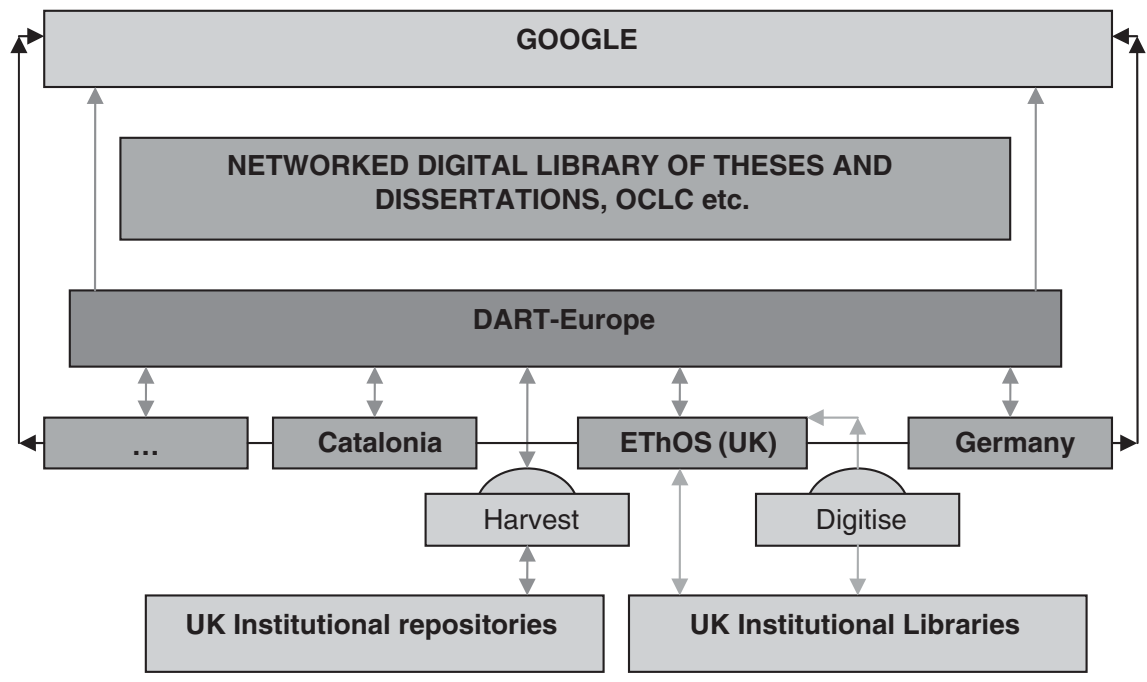

Figure 7. The European e-theses landscape for discovery and retrieval

portal, ${ }^{14}$ supported by LIBER (Association of European Research Libraries) is one such service.

The illustration in Figure 7 shows how European e-theses can be surfaced, discovered and delivered via the DART-Europe portal. This portal is a platform, supported by LIBER, which allows European researchers and users to search for and retrieve research dissertations that have been approved for research degrees in European Universities. The full text of the thesis is stored in the local repository and these are represented as the bottom two layers of the diagram.

EThOS is an emerging UK service that harvests both metadata and some full text for British research theses. There are many other partners who allow the DART-Europe portal to harvest their metadata via the OAI-PMH protocol. At the time of writing, just under 150 universities are represented in the portal from 11 European countries. The number of records harvested by the portal is currently 99,409 .

In Figure 7, the DART-Europe portal harvests the metadata, but not the full text, from all DART-Europe partners who sign the DART-Europe partnership agreement. The same metadata can be/is indexed by Google, both from the individual partner repositories and from DART-Europe.

DART-Europe's preferred model is to work with national or large regional consortia across Europe, in order to harvest metadata into the DART-Europe portal. The way a user uses the portal is illustrated in Figure 8 . When a user searches the DART-Europe portal (1), (s)he conducts a search on the DARTEurope platform (2). Keyword searching in the Title and Description (Abstract) fields are probably the best ways to find information. 
(3)
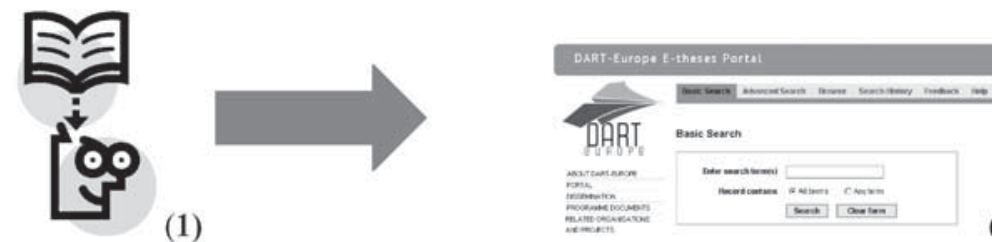

(2)

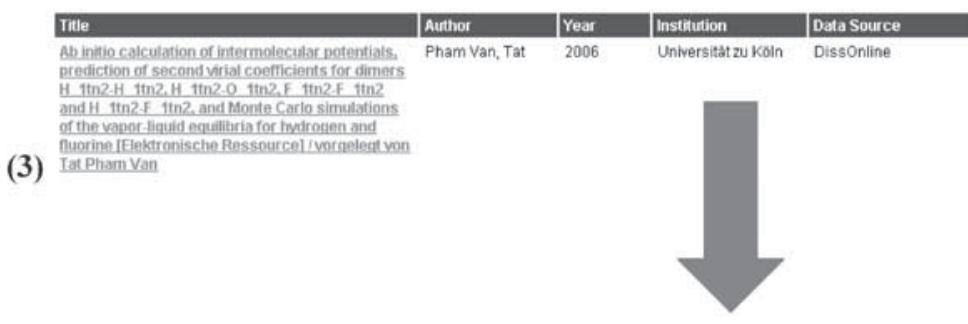

\begin{abstract}
$A b$ initio calculation of intermolecular potentials, prediction of second virial coefficients for dimers $\mathrm{H}_{2}-\mathrm{H}_{2}, \mathrm{H}_{2}-\mathrm{O}_{2}, \mathrm{~F}_{2}-\mathrm{F}_{2}$ and $\mathrm{H}_{2}-\mathrm{F}_{2}$, and

Monte Carlo simulations of the vapor-liquid equilibria for hydrogen and fluorine
\end{abstract}

(4)

Figure 8. Finding a thesis in DART-Europe

Relevant theses, which match the user's query, are retrieved (3) and displayed to the user in a list. Clicking on the relevant entry will produce a fuller record for that thesis, which will contain a URL to the full text of the thesis. Clicking on the URL will transfer the user from the DART-Europe portal to the host repository (4) and the full text will be downloaded and displayed.

If necessary, searches in the DART-Europe portal can be limited to a particular country, a particular language or to a particular institution.

The DART-Europe partnership agreement commits the partners to support various principles:

- DART-Europe is a partnership of research libraries and library consortia who are working together to improve global access to European research theses. DART-Europe is endorsed by LIBER (Ligue des Bibliothèques Européennes de Recherche) as part of the work of the LIBER Access Division, and it is the European Working Group of the Networked Digital Library of Theses and Dissertations (NDLTD).

- The DART-Europe partners help to provide researchers with a single European portal for the discovery of Electronic Theses and Dissertations (ETDs), and they participate in advocacy to influence future European e-theses developments. DART-Europe offers partners 
Table 3. Top two downloads from UCL Eprints, August 2008

Eprint

Downloads

A.H. Kassem (2006) The legal aspects of seaworthiness: current law

104

and development. Doctoral thesis, Swansea University.

K. Paksukcharern Thammaruangsri (2003) Node and place, a study

82 on the spatial process of railway terminus area redevelopment in central London. Doctoral thesis, University of London.

a European networking forum on ETD issues, and may provide the opportunity to submit collaborative funding applications to achieve DART-Europe's vision for ETDs.

- Partners support the following principles:

- DART-Europe will encourage the creation, discovery and use of European e-theses, and will maintain a central portal for e-thesis aggregation and access

- European libraries and consortia are invited to contribute metadata to the DART-Europe portal. Contributors will determine the terms and conditions under which their metadata are contributed

- Partners will help to secure DART-Europe's status as an international network of excellence in information, expertise and resources relating to ETDs.

One of the main deliverables for institutions, who participate in DART-Europe, is visibility for their research outputs. Research theses, which are available in digital form and via Open Access, receive many downloads. In August 2008, the two most downloaded items from the UCL Eprints repository ${ }^{15}$ were doctoral theses (Table 3).

Paper research theses are difficult to locate by users, and are often stored offsite in closed access stores away from the main campus. Access to the full text via Open Access in an electronic repository is good for research and good for the student, because of the visibility that young researchers receive at the start of their careers. It is a compelling vision.

\section{Embedding repositories into the institutional landscape}

For Higher Education Institutions (HEIs) digital repositories are strategic instruments to develop coherent and coordinated approaches to the capture, identification, storage and retrieval of intellectual assets such as datasets, course material and research papers. Many HEIs have now set up digital repositories. 
SHERPA-LEAP, a consortium of 13 institutions, is one of the first networks of e-print repositories in the United Kingdom to be fully functional and operating. ${ }^{16}$ The SHERPA-LEAP leadership has been concerned about the strategic commitment of Higher Education institutions to repository sustainability. The consortium sought a study from RAND Europe, funded by the JISC, to provide an assessment of the current awareness and attitudes of stakeholders regarding digital repositories in three case study institutions. ${ }^{17}$

The main purpose of this report was to complement the holistic espida ${ }^{18}$ approach by focusing on the customer and stakeholder perspective. The findings therefore should be of use to decision-makers involved in the development of digital repositories. The study's approach was entirely based on consultations with specific groups of stakeholders in three institutions through interviews with specific individuals. The consultants held two workshops with the EMBRACE (the name of the London project) board to share findings. In the study, they tried to answer four questions. Here, they briefly summarise their answers to these questions and delineate several higher level lessons for decision-makers in HEIs.

Q1. To what extent are the institutions strategically committed to repository sustainability, specifically considering the institutional stewardship of digital assets?

A. Overall, the interviews seemed to validate the hypothesis of the EMBRACE project board that digital repositories are currently underutilised, and that there are significant barriers to strategic commitment. However, the findings revealed a complicated picture of disciplinary differences, departmental and institutional differences, heterogeneous between and within stakeholder groups. This relative lack of strategic commitment cannot be attributed to fundamental disapproval of the concept of digital repositories; there does not seem to be any stakeholder group that opposes the development of, and investment in, this infrastructure. Rather, as echoed in the espida handbook (2007), the potential benefits are intangible, and they will not be visible until a critical mass is reached, and there is yet little (quantitative) evidence that they will outweigh the costs.

Q2. What are the motivations for different stakeholders to support digital repositories?

A. HEIs currently lack a coherent vision of how digital repositories can assist these organisations in accomplishing their mission. Partly this is due to the notion that a digital repository is a multi-purpose technological concept, which facilitates collecting, registering, 
archiving, linking, preserving and providing access to digital objects. The interviews revealed a range of different motivations for investing in digital repositories. Different groups of stakeholders seem to have a different picture of what a repository is, and what it should or could do. Although precarious given the small sample of interviewees, some generalisations can be made.

- Library staff strongly supported the increased accessibility of research outcomes and gaining more control over the archiving and preservation of institutional intellectual assets.

- Senior management and departmental heads predominantly support the opportunities offered by digital repositories to facilitate collecting and organising (annual) research output as an input to research assessments for funding (e.g. the new Research Excellence Framework [REF] in the UK replacing the Research Assessment Exercise [RAE]).

- Researchers tend to be more motivated by publishing their results in prestigious journals, not least because of funding, tenure and promotion considerations. It is more common to disseminate unpublished papers in some disciplines (e.g. economics) than in others (e.g. biomedical sciences).

It seems to be mainly staff with externally-facing functions (e.g. External Affairs) that are most motivated by the opportunities to showcase the institution's research in a centralised location.

Q3. If any, what are the barriers to the embedding of digital repositories in institutional strategy?

A. Digital repositories may well be victims of their own success. Given their range of potential benefits, stakeholders have different views of how to use digital repositories. The absence of a shared understanding of digital repositories may be one of the main barriers to embedding these systems in HEIs' daily operations. The study considered buy-in from the wider community as a crucial condition for achieving a sustainable digital repository with a critical mass. One factor in this is the dependence of the repository on the research community for its content. However, it is very difficult to provide evidence of all these benefits.

Even if most of the barriers identified in the EMBRACE report e.g. the lack of awareness, a technology that is in its infancy, risks of reputational damage, or the administrative burden of depositing can be overcome, one major challenge remains for digital repositories, namely the lack of incentives to the wider institutional 
community to provide content for these repositories. Funding, tenure and promotion are important drivers for researchers; digital repositories will be embedded in HEIs' daily operation when depositing research output contributes to any of the abovementioned factors - in short, when the incentives of those depositing are aligned to the strategic objective of the repository.

Q4. Which measures can be considered for pursuing strategic commitment to resourcing and sustaining repositories of digital assets within HEIs?

A. The interviewees identified a range of interventions to overcome some of the barriers that exist to embedding digital repositories and to achieving viable and sustainable repositories going forward. In some cases, these followed logically from the barriers that they identified earlier. For instance, given the lack of clarity among stakeholders about what a digital repository is or should be, several suggested targeted information campaigns to engage with the stakeholder community. In general, the interventions suggested by the interviewees could be categorised in two main areas: those related to developing a strategy and creating a shared vision of digital repositories across the institution; and those related to achieving buy-in and communicating with the key stakeholders. The first category consisted of recommendations about reconciling the competing visions of what a digital repository is, allocating dedicated resources to support the process of depositing, and aligning the incentives of the stakeholders with the strategic objectives of the repository. The second category consists of different ways of communicating with the stakeholders, informing them of what the digital repository is and seeking their views going forward as to how to improve the repository strategy and the services offered by the repository.

While undertaking this study, a clear theme emerged. There appears to be a misalignment between the objectives of the repository and the needs of the different groups of stakeholders. It is hard to establish whether this problem comes from the lack of a clear repository strategy or because the stakeholders are unaware of the strategic objectives. The views of interviewees pointed in both directions. Certain mechanisms that could address this problem are undertaken to different degrees across institutions; for example, aligning the incentives of stakeholders with the objectives of the repository, informing the stakeholders of the repository, and overcoming copyright constraints. 
All of this also has an important knock-on effect. As the digital repository depends on engagement from the stakeholders in order to achieve a critical mass and show the value it adds to the institution, a lack of buy-in from the stakeholders could undermine the projects in the medium to longer term.

While espida has proved a useful tool to support the development of repository projects and attract funding, the EMBRACE study indicates that stakeholder buy-in is a key factor in successfully embedding digital repositories in institutional strategy and day-to-day operation. In short, the strategies of digital repositories clearly need to reflect the needs of stakeholders and align the repository objectives with their incentives.

In the report, the authors gave some indications of how the motivations of stakeholders differ (Chapter 2) and the different barriers to embedding digital repositories that stakeholders perceive (Chapter 3). Digital repository managers could map their potential objectives against the motivations of stakeholders and the barriers that they perceive. This would allow repository managers to adjust their strategy to specific motivations as they receive feedback from groups of stakeholders, to communicate clearly what they are trying to achieve, and to devise specific and targeted interventions to overcome the barriers relevant to the stakeholder groups that they seek to engage. This in turn could lead to sustained support from the institution and the embedding of the repository in institutional strategy.

\section{Conclusion}

Open Access has made some inroads into the way that academic outputs are disseminated from Europe and new tools and services are beginning to appear to support this development. In the e-books arena, there is much uncertainty as to the way forward. E-books are still immature and much development work - e.g. for tools, delivery platforms and business models - remains to be done. At the institutional level, the EMBRACE report shows that Open Access modes of delivery are not yet embedded in strategic planning. The road to a digital Europe is characterised by many opportunities, new developments, and uncertainties. It is not yet clear how the new landscape will develop.

\section{References and Notes}

1. See http://ec.europa.eu/research/science-society/page_en.cfm?id=3459

2. M. Cockerill, How accessible is NHS-funded research to the general public and to the NHS's own researchers? at http://www.biomedcefsntral.com/ openaccess/inquiry/refersubmission.PDF

3. See http://www.library.nhs.uk/aboutnlh/review

4. See http://www.sherpa.ac.uk

5. See http://www.eua.be/index.php?id=396 
6. See http://www.opendoar.org

7. Reproduced in http://www.slaw.ca/2008/02/28/the-harvard-mandate/

8. Quoted in http://www.libraryjournal.com/info/CA6533543.html

9. See http://igelu2008.csic.es/conference/programme.htm

10. Ivy Anderson, California Digital Library; Eddie Anand, National Library of New Zealand; Paul Ayris, UCL (University College London); Dale Flecker, Harvard University; Lothar Nunnenmacher, ETH Zurich; Marco Streefkerk, University of Amsterdam; Margery Tibbetts, California Digital Library; Bob Wolven, Columbia University; Jennifer Younger, University of Notre Dame; Oren Beit-Arie, Ex Libris; Shlomo Sanders, Ex Libris; Yohanan Spruch, Ex Libris; Kathryn Harnish (joined October 2007), Ex Libris; Ted Koppel (through November 2007), Ex Libris.

11. See http://www.ucl.ac.uk/slais/research/ciber/superbook/

12. See http://www.SonyStyle.co.uk/Reader

13. See http://eprints.ucl.ac.uk/4702/ and especially Figure 8.

14. See http://www.dart-europe.eu

15. See http://eprints.ucl.ac.uk

16. See http://www.sherpa-leap.ac.uk/

17. S. Hoorens, L. Villalba-Van Dijk and C. Van Stolk, Embracing the Future: Embedding Digital Repositories in the University of London (Unpublished Report to the SHERPA-LEAP consortium, 2008). I am grateful to the authors of this study, particularly to Stijn Hoorens, for the possibility of working with them on this project and of replicating parts of their Executive Summary here in this paper.

18. Espida was a project funded by the Joint Information Systems Committee (JISC) to make the can help make business cases for proposals that may not necessarily offer immediate financial benefit to an organisation, but rather bring benefit in more intangible spheres, see for instance http:// www.gla.ac.uk/espida/documentation.shtml (accessed August 2008).

\section{About the Author}

Dr Ayris has been Director of UCL Library Services since 1997. He is also the UCL Copyright Officer. He is a member of the LIBER (Ligue des Bibliothèques Européennes de Recherche), SPARC Europe and DRIVER Boards. He chairs LIBER's Access Division, the OAI Organizing Committee for the Cern Workshops on Scholarly Communication, and he chaired the 2006 European Repositories meeting in Glasgow. He also chairs the UK's SHERPA Management Group. He is a member of the JISC's Repositories and Preservation Advisory Group, of the JISC's Journals Working Group, of the SCONUL/CILIP Health Strategy Group and of the CURL/SCONUL Joint Scholarly Communications Group. He has a PhD in Ecclesiastical History and publishes on English Reformation Studies. 